\title{
QUESTÕES TERMINOLÓGICO-CONCEITUAIS NO CAMPO DA TRADUÇÃO AUDIOVISUAL (TAV) ${ }^{1}$
}

\author{
Eliana P. C. Franco e Vera Santiago Araújo
}

\section{Tradução Audiovisual (TAV)}

Para inaugurar um número sobre TAV, nada mais propício do que começar com a própria definição da área. Na introdução do volume especial do The Translator de 2003, volume 9, número 2, intitulado Screen Translation, Yves Gambier tenta justificar a opção por screen (tela) ao invés de audiovisual. Ele explica que os primeiros estudos na área se referiam ao termo "tradução de filmes" ou film translation porque enfatizavam o cinema, a tela grande. Desde o momento em que o VHS se tornou popular, no final dos anos 1980 s, e a atenção foi deslocada para a tradução realizada nesse meio, o termo "tradução audiovisual” (TAV) ou audiovisual translation (AVT) passou a vigorar. "Audiovisual" significava o cinema, a televisão, o vídeo e, curiosamente segundo Gambier, até mesmo o rádio, chamando assim a atenção para a dimensão multissemiótica de todos os programas transmitidos. Já o termo screen translation focava no meio de exibição de programas de TV, do computador e de filmes do cinema, a tela. $\mathrm{O}$ autor ainda menciona o termo multimedia translation, ou "tradução multimídia", como uma alternativa a "audiovisual", mas reconhece que o mesmo é bastante confuso porque pode ser usado para se referir a diferentes meios, gêneros e códigos (verbal e visual), como o teatro, os quadrinhos, filmes, páginas da web, jogos de computador etc.

O mais interessante, na verdade, é que o autor continua sua introdução do volume “Screen” Translation usando AVT (audiovisual translation), o que reflete sua própria indefinição terminológica. A apresentação dos tipos de TAV não é menos confusa, e a lista é composta por: legendagem interlinguística ou legenda aberta (interlingual subtitling ou open caption), legendagem bilingue (bilingual subtitling), dublagem (dubbing), dublagem intralingual (intralingual dubbing), interpretação consecutiva (consecutive interpreting), interpretação simultânea (simultaneous interpreting), interpretação de sinais (sign language interpreting), voice-over ou meia-

\footnotetext{
${ }^{1}$ A seção deste artigo dedicada ao modo de tradução voice-over é parte dos trabalhos publicados de Franco (2000 e 2001) e Franco, Matamala \& Orero (2010).
} 
FRANCO \& ARAÚJO - Questões terminológicas e conceituais ...

dublagem (voice over ou half dubbing), comentário livre (free commentary), tradução à prima vista ou simultânea (simultaneous or sight translation), produção multilinguística (multilingual production), legendagem intralinguística ou closed caption (intralingual subtitling ou closed caption), tradução de roteiro (scenario/script translation), legendagem ao vivo ou em tempo real (live or real time subtitling), supra-legendagem ou legendagem eletrônica (surtitling) e audiodescrição (audiodescription), nessa ordem. Apesar dessa gama variada de modalidades de TAV citadas por Gambier, na apresentação dos artigos que compõem o volume percebemos que todos tratam da legendagem (aberta e para surdos) e/ou da dublagem, e apenas um fala da interpretação para a TV.

Essa taxonomia nebulosa proposta pelo autor, que veio substituir as primeiras tentativas de Gambier de classificar as modalidades de TAV visual em $1996^{2}$, coloca em xeque, em primeiro lugar, o próprio termo "audiovisual”, pois a tradução à prima vista ou simultânea e a tradução de roteiro se caracterizam por serem: a primeira, uma tradução de documento escrito para o discurso oral e a segunda, uma tradução de um documento escrito para outro documento escrito, ou seja, nenhuma delas se caracteriza por acontecer através de uma tela, necessariamente. Por exemplo, uma tradução à prima vista pode acontecer no tribunal, quando o tradutor traduz na hora os escritos do processo na língua nativa para a língua dos acusados estrangeiros; a tradução de roteiro já é, por sua vez, como a de um livro, independentemente do fato de que aquele roteiro será levado às telas do cinema ou ao palco do teatro. Da mesma forma, ele inclui a supra-legendagem ou surtitling, característica do teatro, espaço onde não há a tela, num volume em que, a princípio, tenta focar nas traduções realizadas para a tela.

Outros tipos de TAV citados podem acontecer no meio audiovisual, mas não fazem necessariamente parte dele, como a interpretação consecutiva e a simultânea (por exemplo, numa entrevista de uma reportagem ao vivo ou na cerimônia de entrega do Oscar, respectivamente) e a interpretação de sinais. Outros ainda não constituem diferentes tipos de TAV, como a legendagem ao vivo ou em tempo real. Nesse caso, o que está sendo enfatizado é o tempo em que tais legendas são produzidas, ou seja, ao mesmo tempo em que o discurso a ser traduzido acontece. Porém, essas legendas ao vivo podem ser tanto abertas quanto fechadas, inter ou intralinguais. São apenas um subtipo da modalidade de TAV legendagem. Por fim, alguns tipos mencionados

\footnotetext{
${ }^{2}$ Ele ainda continua sua taxonomia no ano seguinte (2004) à publicação do volume sobre Screen Translation (ver referências bibliográficas).
} 
FRANCO \& ARAÚJO - Questões terminológicas e conceituais ...

recebem "apelidos" que mais confundem a sua definição do que explicam, tais como half dubbing para voice-over e double dubbing para audiodescrição, e ainda outro poderia facilmente estar fora desta lista: free commentary ou "comentário livre", por não se caracterizar como tipo de TAV, pelo menos para as autoras deste artigo, o que será discutido mais tarde.

A luz no fim do túnel para essa complexa classificação é encontrada em Díaz Cintas (2005), em um artigo bastante objetivo sobre Tradução Audiovisual e Acessibilidade. Embora ainda merecedora de algumas ressalvas por parte das presentes autoras, a taxonomia proposta por Díaz Cintas realmente simplifica nosso entendimento sobre a terminologia na área. Segundo ele:

Na sua acepção primária, a TAV foi usada para encapsular práticas de tradução diferentes usadas na mídia audiovisual - cinema, televisão, VHS - nas quais há a transferência de uma língua-fonte para uma língua-meta. A dublagem e a legendagem são as mais populares na profissão e as mais conhecidas pelo público, mas há também outras tais como voice-over, dublagem parcial, narração e interpretação. A tradução para o espetáculo ao vivo foi adicionada a essa taxonomia num estágio posterior e foi assim que a supra-legendagem [surtitling] para a ópera e o teatro também foi incluída. A mudança de língua que acontece em todos esses casos foi um fator decisivo para nomear essas práticas como tradução. $\left(2005\right.$, p. 4) [tradução nossa ${ }^{3}$ ]

Em primeiro lugar, Díaz Cintas deixa claro que o meio audiovisual inclui todos os espaços onde há um sinal acústico e um sinal visual, independentemente de ser transmitido através de uma tela (que pode ser ao vivo ou não) ou de um palco (sempre ao vivo). Desta forma, a designação screen translation limitaria o escopo da tradução audiovisual, excluindo o que acontece fora da tela. Em segundo lugar, Díaz Cintas diminui consideravelmente os tipos de tradução audiovisual, limitando-se aos principais, de onde subtipos emergirão, como, por exemplo, a legendagem para ouvintes (aberta) e a legendagem para surdos (que pode ser aberta ou fechada, como a closed caption), que pertence à modalidade legendagem. O problema que persiste nessa abordagem mais objetiva é a insistência por alguns tipos não característicos do meio audiovisual apenas, como a interpretação, e de outros tipos que não constituem modalidade de TAV, como a narração, na opinião das presentes autoras.

\footnotetext{
${ }^{3}$ In this primary inception, AVT was used to encapsulate different translation practices used in the audiovisual media - cinema, television, VHS - in which there is a transfer from a source to a target language. Dubbing and subtitling are the most popular in the profession and the best known by audiences, but there are some others such as voice-over, partial-dubbing, narration and interpreting. The translation of live performance was added to this taxonomy at a later stage and that is how surtitling for the opera and the theatre has also come to be included. The change of language that takes place in all these cases has been a key factor when labeling theses practices as translation.
} 
FRANCO \& ARAÚJO - Questões terminológicas e conceituais ...

Originalmente conectados, os conceitos de TAV e tradução interlingual realizados através da legendagem, da dublagem e do voice-over tiveram que ser revistos por causa do novo cenário que se impôs desde o começo do novo século, em que leis de acessibilidade para o audiovisual forçaram a tecnologia a pensar em novos recursos que tornassem a comunicação nesse meio acessível a pessoas com deficiência auditiva e visual. Daí surgiu a legendagem para surdos e ensurdecidos (LSE) e, bem mais recentemente, a audiodescrição (AD), destinada ao público cego e com deficiência visual. Como sugere Diaz Cintas ao final da citação acima, o fato de que esses novos recursos se caracterizavam não pela tradução entre línguas, mas entre meios semióticos diferentes - do acústico verbal ou não verbal para o verbal escrito na LSE e do visual para o verbal oral na $\mathrm{AD}$ - representou um entrave para a aceitação de ambos como modalidades de tradução audiovisual por parte da comunidade acadêmica e científica, mas não por parte de alguns pesquisadores famintos por novas e inovadoras fontes de pesquisa, como afirma o autor (2005, p. 4).

Ainda de acordo com o autor, foi graças a uma das mais antigas e citadas taxonomias de tradução, a de Jakobson (1959), que todos pudemos mais confiantes argumentar a favor das duas novas modalidades que se caracterizavam como intralinguais (LSE) e intersemióticas (LSE e AD) da tradução audiovisual, juntamente com as interlinguais já existentes. LSE e AD representaram assim um redimensionamento da área, não apenas pelo fértil campo da pesquisa que propiciaram, mas também pela possibilidade de redefinirmos as outras modalidades como igualmente promotoras de acessibilidade. Como Diaz Cintas coloca melhor do que ninguém:

Eu gostaria de expandir o conceito e argumentar que, em essência, dublar, legendar ou traduzir em voice-over um programa é compartilhar com a ideia de acessibilidade da mesma forma que a LSE e a AD. Apenas os públicos-alvo é que são diferentes. Se o desafio é uma barreira linguística ou sensorial, o objetivo do processo tradutório é exatamente o mesmo: facilitar o acesso a uma fonte de informação e entretenimento anteriormente hermética. Nesse sentido, a acessibilidade se torna um denominador comum que permeia essas práticas. $\left(2005\right.$, p. 4) [ tradução nossa $\left.{ }^{4}\right]$

Em consonância com essas definições propostas por Diaz Cintas, Franco e Araújo organizaram, no ano de 2005, um dossiê sobre tradução audiovisual publicado

\footnotetext{
${ }^{4}$ I would like to expand the concept and argue that, in essence, to lip-sync, to subtitle or to voice-over a programme shares as much the idea of accessibility as SDH or AD. Only the intended audiences are different. Whether the hurdle is a language or a sensorial barrier, the aim of the translation process is exactly the same: to facilitate the access to an otherwise hermetic source of information and entertainment. In this way, accessibility becomes a common denominator that underpins these practices.
} 
FRANCO \& ARAÚJO - Questões terminológicas e conceituais ...

nos Cadernos de Tradução (n. XVI, Edufsc, 2005/2), um número sobre tradução audiovisual para a revista TradTerm (n. 13, 2007) e, agora, têm a honra de participar deste número da Tradução em Revista (PUC-Rio), esperando poder contribuir para facilitar a compreensão da terminologia na área, carente de pesquisas em nosso país.

Para tanto, as seções que se seguem discutem cada modalidade de TAV individualmente, ou pares de modos que se intercalam ou cujo paralelismo se torna inevitável. Levando-se em consideração o que já foi discutido aqui, consideramos como modalidades a legendagem para ouvintes, a LSE, a legendagem eletrônica ou surtitling, a dublagem, o voice-over e a audiodescrição. Apesar de não se caracterizar exatamente como uma modalidade de TAV, mas por ser necessária em alguns momentos em filmes audiodescritos, falaremos um pouco sobre a audiolegendagem na seção sobre audiodescrição. Já a interpretação para a TV, que pode ser consecutiva, simultânea ou de sinais, mas que não consiste em um modo de tradução especificamente audiovisual, não será discutida em sessões distintas, mas mencionada em sessões onde seja necessário e conveniente para o esclarecimento do que consideramos as modalidades de TAV per se.

\section{A Legendagem}

\subsection{A Legendagem para Ouvintes}

A primeira tentativa de propor uma terminologia para a legendagem partiu de Alvarenga (1998). Na proposta não constava a diferenciação entre legendagem para ouvintes e legendagem para surdos. Para a autora, "legendagem" referia-se à legenda interlingual. A nova subdivisão baseia-se na necessidade de diferenciar os dois tipos de legendagem com fins à demarcação de áreas de estudo, já que ambas possuem características singulares, como veremos a seguir.

As legendas para ouvintes atualmente são confeccionadas com o uso de softwares que permitem a marcação ou divisão das falas em legendas (spotting ou cueing), tradução, revisão e pré-visualização do filme legendado. Na época do trabalho supracitado, os softwares de legendagem não eram muito acessíveis aos tradutores. Por essa razão, as legendas eram produzidas no processador de textos Word, com os tempos iniciais e finais sendo marcados com o auxílio de um Time Code Reader (TCR) presente em toda cópia de trabalho de um filme ou programa de TV a ser legendado (Figura 1). O objetivo é a indicação do local exato onde as legendas ficarão localizadas na legendagem final do filme ou programa. 


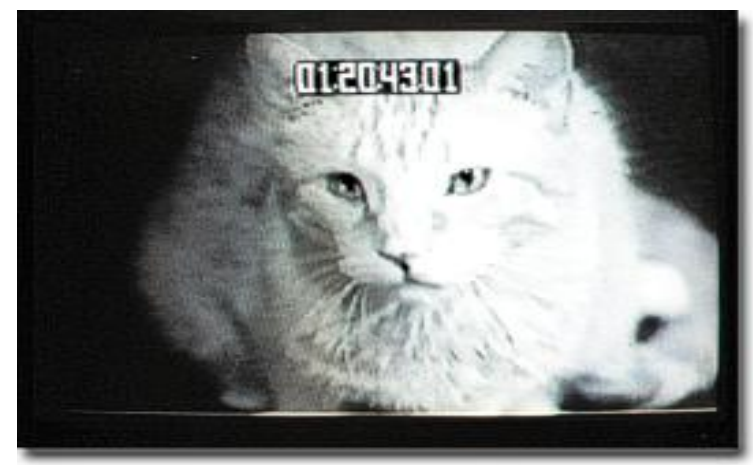

Figura 1: O TCR

O TCR acima mostra que o filme já rodou uma hora, vinte minutos, quarenta e três segundos e está no primeiro quadro ou frame. Um filme de vídeo normalmente possui, aproximadamente, a velocidade de vinte e nove quadros por segundo.

Baseada em sua experiência, Alvarenga começa propondo traduções diferentes para a legendagem (subtitling) e para os profissionais envolvidos (1998, p. 215). Segundo a autora, como a tarefa exige um trabalho de equipe envolvendo diversos profissionais, é preciso nomeá-los diferentemente. Em primeiro lugar, ela cita os dois profissionais que se dividem na tarefa de legendar, o legendador e o legendista. $\mathrm{O}$ legendador é o técnico (ou pode ser um tradutor) que grava as legendas no vídeo, enquanto que o legendista faz a tradução. Para Alvarenga, o termo "legendista" se justifica, porque é o tradutor o protagonista da tradução. Essa diferenciação vem sendo adotada em todos os trabalhos produzidos pelo grupo LEAD, grupo de pesquisa da UECE e por Selvatici (2010). No entanto, há autores que preferem chamar os tradutores para legendas de legendadores (Martinez, 2007 e Carvalho, 2010).

Já a diferenciação entre legendação (o trabalho de tradução) e legendagem (o processo completo até a gravação) não se sustenta nos dias atuais, pois é possível realizar uma legendagem completa com o auxílio de softwares livres. Aqui não serão discutidos os termos referentes aos parâmetros de legendagem (condensação, segmentação, quebra de linha, redução, adição e velocidade de legenda), porque os mesmos serão abordados em outros artigos sobre o tema nesse volume.

\subsection{A Legendagem para Surdos e Ensurdecidos (LSE)}

A legendagem para surdos e ensurdecidos (LSE) é a tradução do inglês SDH (Subtitlting for the deaf and the hard-of-hearing). Esse termo foi sugerido por Selvatici (2010) e por membros da sua banca de mestrado. Não estamos utilizando closed caption para nos referirmos à legendagem para surdos, porque, ao contrário do que muitas 
FRANCO \& ARAÚJO - Questões terminológicas e conceituais ...

pessoas pensam, closed caption não é sinônimo de "legenda para surdos". Esta consiste em um sistema de legendagem fechada ou oculta (o espectador precisa acessá-la no seu controle remoto do aparelho de TV ou DVD) em oposição à legendagem aberta. Closed caption é um modelo norte-americano de legendagem usado em muitos países, inclusive no Brasil. Na Europa, o sistema utilizado é o teletexto. Mais detalhes de como funciona esse sistema podem ser encontrados neste número no artigo de Araújo e Nascimento.

Outro termo ligado à LSE é respeaking, ou seja, é a legendagem ao vivo feita por meio de um programa de reconhecimento de voz. O sistema é bastante utilizado em canais de TV da Europa, onde a pesquisa na área está se desenvolvendo (Ribas \& Romero Fresco, 2008; Romero Fresco, 2009 e 2010). No Brasil, ainda não existe pesquisa acadêmica sobre o assunto, mas a legendagem refalada (Romero Fresco, 2009) ou legendagem por reconhecimento de fala (Orero, s/d) já está sendo usada no Brasil na programação da Rede Globo. Segundo Selvatici (2010, p.32):

\footnotetext{
Essa técnica ainda causa muitos erros na produção das legendas, especialmente quando se trata de palavras homófonas (ex.: censo X senso) ou de palavras que - juntas formam o som de uma terceira palavra ou de uma expressão (ex.: ela tinha X é latinha), mas, à medida que a tecnologia se desenvolve, esses erros tendem a diminuir. Além disso, o custo de formação de um profissional que trabalha com reconhecimento de voz é muito inferior ao de um estenotipista, o que pode contribuir para a disseminação da técnica no Brasil.
}

Como se pode perceber, uma reflexão acadêmica sobre a legendagem refalada ou por reconhecimento de voz e a formação de profissionais na área ainda se faz necessária para a melhoria da qualidade da LSE oferecida no Brasil.

\subsection{A Legendagem Eletrônica (Surtitling)}

A legendagem eletrônica ou surtitling (Bartoll, 2011) é constituída de legendas projetadas em teatros e mostras de cinemas. É usada normalmente em óperas, daí porque alguns a chamam de opera titling (Freddi \& Luraggi, 2011). Segundo Bartoll (2011), não há muitos estudos acadêmicos sobre essa prática profissional tão utilizada no mundo todo. De acordo com o autor, as legendas eletrônicas são chamadas de "supra-legendas" (surtitles) por causa da posição que geralmente ocupam no palco nas peças de teatro, ou seja, acima do palco. Preferimos nos referir a esse tipo de legendagem como legendagem eletrônica, porque a mesma é assim conhecida nos meios culturais brasileiros. Do mesmo jeito que a legendagem refalada, também não há 
FRANCO \& ARAÚJO - Questões terminológicas e conceituais ...

estudos sobre essa modalidade no nosso país, apesar de ser uma prática corrente na tradução de peças de teatro, musicais, óperas e mostras de cinema.

\section{Os Modos de Revocalização: A Dublagem e o Voice-Over}

\subsection{A Dublagem}

A dublagem é uma das modalidades de TAV mais conhecidas pelos brasileiros porque, apesar de ter sua origem no rádio, foi o modo escolhido e amplamente divulgado pela televisão brasileira para divulgar a importação de filmes estrangeiros, especialmente os americanos, outros programas de ficção - como os sitcoms, e mais recentemente até programas que não se encaixam no rótulo ficcional.

Diferentemente de alguns países europeus que elegeram a dublagem por motivos ideológicos, como a Espanha na época de Franco que usou essa modalidade como meio de censura (Ballester, 1999), ou a Alemanha e a França, que ainda lançam mão da dublagem para promover sua língua e cultura, a escolha pela dublagem na televisão brasileira teve um cunho social, ou seja, fazer com que filmes e programas pudessem ser entendidos também pelo público analfabeto, numeroso no país. ${ }^{5}$ Por também se caracterizar pela baixa renda, esse público dificilmente frequenta as salas de cinema, que elegeram a legendagem como principal meio de tradução audiovisual, com exceção dos filmes para crianças, em sua maioria dublados, mas em alguns casos também em versão legendada, para o frequentador adulto que gosta de ouvir o filme na língua fonte.

A dublagem pode ser definida por três características básicas:

1. É uma tradução interlingual de um discurso oral para outro discurso oral, das falas dos personagens de um filme ou programa de ficção pré-gravado. Por esse motivo, é também chamada de "revocalização".

2. Elimina a presença do discurso oral estrangeiro.

3. É regida pelo sincronismo labial, fundamental para fazer com que o públicoalvo acredite na ilusão de que o personagem esteja falando na sua língua. Por causa disso, a dublagem é às vezes chamada, em países de língua inglesa, de lip-sync translation ou simplesmente de lip-sync (tradução de sincronismo labial).

\footnotetext{
5 Para recentes estatísticas sobre o analfabetismo no Brasil, acesse http://ultimosegundo.ig.com.br/educacao/analfabetismo+cai+pouco+e+atinge+97+da+populacao/n12377 70936261.html. Acessado em 21 nov. 2011.
} 
FRANCO \& ARAÚJO - Questões terminológicas e conceituais ...

A tradução para a dublagem segue, então, duas etapas: a tradução do roteiro com especial atenção ao sincronismo labial e a gravação do roteiro traduzido, no qual adaptações no texto que não distorçam o significado do discurso são feitas pelo diretor de dublagem em prol do sincronismo labial.

A necessidade de make believe produzida pela dublagem não é apenas promovida pelo sincronismo labial, mas também pela voz escolhida para representar cada personagem na cultura de chegada, que deve se assemelhar à voz do ator/atriz que o representa, e pela interpretação que lhe é dada no contexto fílmico. Por causa disso, os dubladores são atores credenciados, uma vez que a ficção exige uma encenação de voz, a mimetização da dramaticidade do texto-fonte e não apenas uma locução do texto traduzido. A ilusão fabricada pela dublagem de que tal voz feminina ou masculina no português brasileiro pertence a tal ator/atriz estrangeiro(a) se reflete no choque que já sentimos ao ouvir uma voz diferente vinda da boca desse ator ou atriz, o que geralmente provoca reações negativas de ardorosos fãs e espectadores.

Apesar de, por longos anos, a dublagem ter sido associada a produtos audiovisuais estritamente de ficção, a televisão paga brasileira tem introduzido um quadro diferente recentemente, em que programas classificados como de não-ficção, como alguns reality shows e reportagens, estão sendo dublados ao invés de legendados, e outros são ainda dublados e legendados. O canal Fox Life é um dos que mais têm introduzido essa prática desde 2007. A dublagem chega a exagerar no sotaque do falante, mas é menos exigente quanto ao sincronismo labial, fazendo com que, por vezes, o personagem pareça um tanto caricato. Dois exemplos desse novo cenário são programas de viagem, no qual o guia/apresentador é quase uma atração à parte, e programas adultos com tema sexual, que passam tarde da noite. Um dos principais motivos dessa mudança, discutida em matéria recente na Folha de São Paulo (outubro de 2011) é o aumento do poder aquisitivo da classe C no Brasil, que começou a consumir a TV paga. Outro motivo não menos importante é o apelo do público com deficiência visual pelo maior acesso aos canais da TV paga, tradicionalmente legendados.

Preferências por um ou outro modo à parte, a melhora da qualidade de vida das classes mais baixas da população e a questão da acessibilidade que agora vigora nos meios de comunicação parecem desestabilizar um quadro que se apresenta há muito tempo na televisão: a associação da modalidade de tradução dublagem ao gênero ficção. Talvez esse novo quadro represente também uma nova demanda por pesquisas sobre a 
FRANCO \& ARAÚJO - Questões terminológicas e conceituais ...

dublagem, bastante escassas tanto no Brasil quanto no exterior. O grande marco dos estudos sobre dublagem veio com o primeiro livro sobre o assunto, de autoria de Candice Whitman (1992), seguido por Agost (1999) e Chaume (2004), que parece ser o grande e único nome na área no momento. No Brasil, a dissertação de mestrado de Franco (1991) e a tese de doutorado de Araújo (2000) marcaram um novo tema de interesse, mas pesquisas sobre dublagem se mantiveram limitadas a estudos de caso que não chegaram a desafiar a definição e o uso dessa modalidade de TAV.

\subsection{O Voice-over}

Assim como a dublagem, o voice-over é pré-gravado, o que também representa a revocalização de um discurso oral em língua estrangeira para um discurso oral na língua da tradução, mas sob uma perspectiva completamente diferente, o que não permite que seja subordinado à dublagem ou classificado como um subtipo desta. O voice-over se caracteriza:

1. por ser uma tradução audiovisual interlingual usada para produtos audiovisuais estritamente pertencentes ao gênero de não-ficção, tais como documentários, noticiários com entrevistas pré-gravadas, programas de entrevistas pré-gravados, debates políticos etc. Tradicionalmente, os países que costumam usar a dublagem para a ficção tendem a usar o voice-over para programas de não-ficção. O objetivo principal dessa tradição é dar prioridade à língua da cultura receptora, como acontece na Alemanha e França;

2. pela ausência de sincronismo labial, embora seja de extrema importância a sincronia com a duração do discurso em língua estrangeira e com a imagem. Em relação à imagem, podemos falar em sincronismo cinético, quando o discurso deve combinar com os movimentos do corpo (por exemplo, quando o falante está apontando para algo) e sincronismo de ação, que impõe uma certa ordem no discurso do falante, limitando inversões sintáticas que poderiam ocorrer para uma melhor fluidez na língua-alvo; e

3. pela co-presença do discurso em língua estrangeira, em volume baixo, ao qual se sobrepõe o discurso em língua de chegada.

Bem menos conhecido entre o público brasileiro por sua pobre divulgação na televisão, que se resume a poucos programas sobre viagens e documentários nos canais pagos, essa modalidade de TAV nunca recebeu a devida atenção de pesquisadores nem no Brasil nem no exterior até os trabalhos pioneiros de Franco (2000, 2001) e Franco, 
FRANCO \& ARAÚJO - Questões terminológicas e conceituais ...

Matamala \& Orero $(2010)^{6}$, que vieram elucidar o termo, tão confundido com seu conceito originado nos Estudos Fílmicos, e demonstrar quão equivocadas eram suas definições dentro dos Estudos da Tradução, que teimavam em reduzi-lo à tradução literal do conteúdo informativo de programas de não-ficção.

\subsubsection{O termo voice-over nos Estudos Fílmicos}

No seu glossário de termos fílmicos, Harrington define voice-over como "qualquer linguagem falada que não parece vir de imagens na tela" (1973, p. 165). ${ }^{7}$ Em outras palavras, voice-over é definido como uma técnica narrativa na qual a voz de um narrador invisível é ouvida sobre imagens diferentes e com propósitos diferentes. Pensemos, por exemplo, na voz expositiva do narrador em um documentário sobre a vida dos animais e na voz acusativa do narrador dirigida a um dos prováveis suspeitos de cometer o crime em um filme de ficção. Deste modo, é comum na terminologia fílmica falarmos sobre os voice-overs de um documentário ou de um filme, significando, por exemplo, todas as sequências do discurso cujo falante não pode ser visto.

Da mesma forma, essa voz que vem de fora da tela também pode ser reconhecida como pertencente a um personagem que está narrando a história em primeira pessoa, ou que aparece na tela mas não expressa seus pensamentos de forma explicitamente verbalizada, isto é, quando as palavras não saem de sua boca enquanto as ouvimos. Podemos pensar aqui no chamado "fluxo de consciência" que acontece em alguns filmes, ou no momento em que um personagem lê uma carta silenciosamente, sem que nenhuma palavra seja pronunciada por seus lábios, mas apenas ouvida pelo espectador. Nesse caso, o cinema prefere chamar essa narrativa de voice-off, pois se refere ao posicionamento temporário de uma voz reconhecível, que pode a qualquer momento tornar-se on screen, ou seja, quando palavras saem da boca do personagem que vemos na tela. Desse modo, podemos dizer que a narração em voice-over acontece geralmente em terceira pessoa e quando o narrador é invisível, e a narração em voice-off acontece quando o narrador coincide com um dos personagens do filme ou programa. Em última instância, voice-over e voice-off como técnicas narrativas significam "voz

\footnotetext{
${ }^{6}$ A discussão apresentada aqui é parte dos três trabalhos mencionados, a saber, a tese de doutorado de Franco (2000), seu artigo na Target (2001) e seu livro em co-autoria com Anna Matamala e Pilar Orero (2010), todos listados nas referências bibliográficas.

${ }^{7}[. .$.$] any spoken language not seeming to come from images on the screen. [tradução nossa]$
} 
FRANCO \& ARAÚJO - Questões terminológicas e conceituais ...

sobre imagem" e podem ocorrer em produtos audiovisuais tanto no gênero ficcional quanto no não-ficcional.

\subsubsection{O termo voice-over nos Estudos da Tradução Audiovisual}

Nos Estudos da Tradução, o interesse pela TAV começou na década de 1980, atingindo seu auge na década de 1990. O termo voice-over foi arbitrariamente tomado por empréstimo da área dos Estudos Fílmicos para se tornar uma modalidade de TAV na nova área de interesse, a ser aplicado em produtos audiovisuais de não-ficção, uma vez que é comumente usado em documentários, nos quais a narração em voice-over suscita um apelo à credibilidade e veracidade do produto audiovisual.

Uma vez importado para a área da TAV, o voice-over passou a significar uma voz não sobre imagens, como nos Estudos Fílmicos, mas sobre outra voz, ou seja, a voz da tradução sobre a voz do discurso original de entrevistados ou de falantes solitários na tela. A co-existência dos discursos em língua-fonte e língua-alvo na tela se dá através da sobreposição da voz da tradução na voz traduzida, esta última em volume baixo, quase inaudível, para não comprometer o entendimento da primeira. Outra característica é o atraso de um a dois segundos sempre observado na voz da tradução, que corrobora com o efeito de credibilidade desejado e produzido pela gravação, influenciando o espectador, de forma bem sutil, a acreditar que o que se diz na língua estrangeira é exatamente o que está sendo reproduzido na sua língua.

A co-existência da mesma denominação para dois conceitos diferentes em duas áreas distintas, mas relacionadas, resultou numa confusão terminológica entre os estudiosos da tradução audiovisual, que sempre demonstraram certo grau de dificuldade ao tentar definir a nova modalidade e suas características, e por isso sentiram necessidade de comparar o termo a outros tipos de tradução ou até a outros discursos narrativos.

Em um levantamento sobre o termo voice-over na literatura em Tradução Audiovisual (Franco, 2000 e Franco, Matamala \& Orero, 2010) foi possível obsevar diferentes abordagens, as quais refletem a indefinição teórica sobre o termo por parte de estudiosos e profissionais da área, que ora tende para o processo tradutório do voiceover e ora tende para o processo de gravação e apresentação da tradução em voice-over. Para eles, a tradução em voice-over é definida como ou comparada com: uma categoria de revocalização, assim como a dublagem; um tipo de dublagem, seja ela dublagem não sincronizada ou sem sincronismo labial, meia-dublagem ou até dublagem sincronizada; 
FRANCO \& ARAÚJO - Questões terminológicas e conceituais ...

legendagem ou legendagem oral; um tipo de interpretação; tradução em sincronismo; tradução falada; tradução ao vivo; tradução simultânea; um tipo de narração; comentário gravado; comentário lido; discurso em off; narrativa ou discurso do entrevistado em off, dentre outros. Uma discussão mais completa dessas comparações pode ser encontrada em Franco, Matamala \& Orero (2010). Aqui, chamaremos a atenção para diferenças mais predominantes, com o intuito de chegar a uma definição clara sobre o termo voice-over e sua acepção na área de TAV.

\subsubsection{Voice-over e legendagem}

A comparação da tradução em voice-over com legendagem se refere à co-presença de dois códigos linguísticos — o texto fonte estrangeiro e sua tradução. A comparação com legendas orais, por sua vez, tem a ver com o fato de que as versões em voice-over tendem a ser mais reduzidas do que seus originais devido ao fato de que necessitam estar em sincronismo com a duração do discurso estrangeiro audível e com a imagem.

\subsubsection{Voice-over e interpretação}

Quando se compara a tradução em voice-over com a interpretação ou, como é chamada por alguns estudiosos, com a tradução em sincronismo ou até com a tradução ao vivo, tradução falada ou tradução simultânea, dá-se ênfase para a dimensão de apresentação das versões em voice-over, ou seja, de como elas chegam ao público receptor - em simultaneidade com o discurso em língua estrangeira, e para o desempenho mimético daqueles que emprestam suas vozes para as pessoas que aparecem na tela.

Contudo, em nenhum momento a comparação entre tradução em voice-over e interpretação deve sugerir que a primeira é realizada ao vivo. A tradução em voice-over, bem como a dublagem, são roteirizadas e gravadas anteriormente à exibição do produto audiovisual, enquanto que a interpretação consecutiva e/ou simultânea sempre acontece em eventos ao vivo, que por sua vez nem sempre acontecem no meio audiovisual. ${ }^{8} \mathrm{O}$ material de um produto audiovisual (p. ex., entrevistas de um documentário) a ser traduzido em voice-over pode ainda pertencer a um produto acabado ou editado (voiceover para pós-produção) ou a um produto ainda por ser editado (voice-over para

\footnotetext{
${ }^{8}$ Kaufmann (1995), intérprete experiente para a televisão, faz distinção entre os modos de tradução ao vivo usados na transmissão in situ (interpretação consecutiva e simultânea) e os modos de tradução gravados, usados em programas en aval, ou gravados antes de sua exibição.
} 
FRANCO \& ARAÚJO - Questões terminológicas e conceituais ...

produção). Neste último caso, o tradutor para voice-over acaba trabalhando em entrevistas ou partes delas que talvez não sejam transmitidas no produto final.

\subsubsection{Voice-over e dublagem}

As comparações entre a tradução em voice-over e dublagem não-sincronizada ou sem sincronismo labial e ainda meia-dublagem claramente se referem ao modo como as traduções em voice-over são apresentadas ao espectador, ou seja, sem o sincronismo labial entre a voz traduzida e a voz tradutora. A comparação da tradução em voice-over com a dublagem sincronizada refere-se: a) ao paralelismo entre a duração do discurso traduzido e a duração do discurso tradutório, em que o último deve começar alguns segundos atrasado e acabar antes ou ao mesmo tempo em que o primeiro acaba; e b) ao paralelismo linguístico entre o discurso tradutório e o traduzido, no qual termos como nomes próprios reconhecíveis pelo público receptor na língua estrangeira devem ter suas traduções reproduzidas em simultaneidade com sua menção pelo falante estrangeiro.

\subsubsection{Voice-over/voice-off}

A ideia de que traduções em voice-over são exemplos de discurso em off é questionável na teoria fílmica se levarmos em consideração que a maioria dos profissionais do cinema não veem voice-off como um recurso cinematográfico permanentemente “desencarnado.” De acordo com Doane (1985, p. 167) a voz-off é sempre "submetida ao destino do corpo, porque ela pertence ao personagem." Em contraste, o discurso em voice-over pertence a uma voz sem corpo fora do espaço diegético.

Desta forma, quando visto pela perspectiva das estratégias tradutórias, quando o falante/entrevistado/talking head está enquadrado na tela, a tradução em voice-over trabalha como um eco da fala dessa pessoa, reproduzindo o que ela está falando. Um dos recursos é o frequente uso do pronome pessoal "eu" nas versões em voice-over, o que neutraliza a presença de um leitor da tradução, embora sua presença seja óbvia, e deve assim ser, para o argumento da credibilidade embutido nesse tipo de tradução. Para a compreensão do espectador da cultura de chegada, o eco é o que importa. O mimetismo da voz original que será dada ao eco no momento de sua gravação é outra estratégia de identificação importante para a credibilidade de traduções em voice-over, uma vez que ambos coexistem no momento da transmissão do produto audiovisual. 
FRANCO \& ARAÚJO - Questões terminológicas e conceituais ...

\subsubsection{Voice-over e narração / comentário}

Tópico já amplamente debatido por Franco em 2000, 2001 e por Franco, Matamala \& Orero, em 2010, é a associação entre voice-over e narração/comentário estabelecida pelos Estudos Fílmicos, a qual resulta na ideia de que comentários traduzidos, típicos de documentários, são exemplos de traduções em voice-over. Se assumirmos que as versões em voice-over são realizadas através da gravação da voz da tradução sobre a voz traduzida, que permanece audível, não há como aceitar que comentários ou narrações sejam exemplos de tradução em voice-over. A ausência da co-existência do discurso original nos comentários de programas traduzidos não deixa claro se esses comentários em particular são traduzidos ou não. $\mathrm{Na}$ prática, os comentários de programas traduzidos podem ser originados de três formas distintas: a) uma tradução mais literal do comentário original; b) uma tradução mais adaptada ou domesticada do comentário original; e c) uma criação de um comentário que não existe no programa original. Em todos esses casos, o comentário continua sendo apresentado como um tipo de discurso diferente do conteúdo das entrevistas, por exemplo, que é o verdadeiro material submetido à tradução em voice-over.

A narração (mais usada para o gênero de ficção) e o comentário (mais usado para o gênero de não-ficção) são definidos por estudiosos do cinema como sequências de discurso por falantes invisíveis sobre imagens do programa (Rabiger, 1998). Ainda hoje definidos como modalidades de tradução audiovisual por importantes nomes da tradução audiovisual, a narração se caracteriza como um voice-over estendido (Luyken et al. 1991) que deve ser aplicado a monólogos por entrevistados de um programa, com um estilo mais formal e com a possibilidade de uso da terceira pessoa, ou seja, de ser apresentado em discurso indireto. Já o comentário apresenta um estilo menos formal e pode adaptar o conteúdo original, sendo apresentado em discurso direto. Não importa exatamente a diferença entre um e outro, a questão aqui é que é infrutífero diferenciarmos a modalidade em voice-over e em voice-over estendido porque ambos se referem à versão traduzida de uma entrevista sendo lida sobre a versão original, com o número de vozes e o estilo sendo os elementos que diferenciam entre o monólogo e o diálogo traduzidos. No caso do uso de discurso indireto para respostas na forma de monólogos na tela, este deve ser visto como uma estratégia da tradução em voice-over, que permite que a resposta do entrevistado seja mais manipulada e até resumida se introduzida por "a testemunha disse que..." ou "todos responderam da seguinte forma". 
FRANCO \& ARAÚJO - Questões terminológicas e conceituais ...

Assim, tipos de discurso presentes em alguns produtos audiovisuais, como a narração e o comentário, não podem ser confundidos com modalidades de TAV. Num documentário formado por entrevistas de testemunhas (seja em forma de diálogo ou de monólogo) e pelo discurso em voice-over (no sentido dos Estudos Fílmicos) de um comentarista invisível, o material a ser traduzido em voice-over geralmente é a entrevista, que deixa original e tradução audíveis, enquanto a tradução mais ou menos literal do comentário será apresentada como uma voz única, ainda como um discurso em voice-over, mas na língua de chegada. Franco, Matamala \& Orero (2010) sugeriram nomear o processo tradutório de comentários e narrações de off-screen dubbing, ou dublagem off-screen, que remete a um processo de adaptação com um determinado grau de proximidade do original (desde extremamente próximo a um comentário inventado) e que é apresentado exclusivamente na língua-alvo.

\subsubsection{O conceito de tradução em voice-over}

Pelo discutido acima, a definição dessa modalidade pouco usada no Brasil, e agora também sendo substituída pela dublagem nos canais pagos, mas bastante frequente na TV europeia, não parece ser tão simples ou direta quanto a de outras modalidades. Afinal, o que define o conceito de tradução em voice-over é um conjunto de características, a saber:

1. é aplicada geralmente a programas audiovisuais considerados de não-ficção (na Polônia, até bem recentemente, a tradução em voice-over era usada para todos os gêneros audiovisuais);

2. traduz as palavras de entrevistadores/entrevistados (diálogos) e dos famosos talking heads ou "cabeças falantes" que monologam na tela;

3. é a revocalização de um texto em outra língua, ou de uma voz tradutora sobreposta a uma voz traduzida;

4. é a tradução oral ou falada que é apresentada simultaneamente e em sincronismo com a duração do discurso fonte, com palavras potencialmente reconhecíveis e com as imagens;

5. não apresenta sincronização labial;

6. frequentemente começa poucos segundos após a fala original;

7. é preparada e gravada antes da transmissão do programa, nunca ao vivo;

8. é derivada de material editado ou não editado;

9. pode traduzir o conteúdo de forma mais ou menos próxima do original; 
10. pode personificar o falante original através da primeira pessoa ou reportar suas palavras através do discurso indireto ou da terceira pessoa;

11. reproduz características miméticas da fala do texto fonte até um certo ponto (sotaque, idade, emoção, entonação, gênero, ênfase);

12. mantém o dono da voz invisível.

\section{A Audiodescrição (AD)}

A audiodescrição (audiodescription) é a tradução em palavras das impressões visuais de um objeto, seja ele um filme, uma obra de arte, uma peça de teatro, um espetáculo de dança ou um evento esportivo. O recurso tem o objetivo de tornar esses produtos acessíveis a pessoas com deficiência visual. A AD pode ser pré-gravada ou ao vivo. A AD pré-gravada é geralmente usada em filmes, programas de TV e obras de arte, enquanto a $\mathrm{AD}$ ao vivo é acontece em eventos e no teatro.

A AD pré-gravada pressupõe um roteiro, o qual será gravado por um locutor. No caso de filmes e programas de TV, a audiodescrição é normalmente inserida no intervalo entre os diálogos, evitando, sempre que possível, a sobreposição com as falas do texto fonte. Tanto o roteirista quanto o locutor são chamados de audiodescritores. Os elementos a serem audiodescritos seriam, segundo Jiménez (2010, p. 70), em três níveis: a) o narratológico (elementos visuais verbais, como os créditos e o logo dos produtores do filme, e não verbais, como os personagens, os ambientes e as ações); b) o cinematográfico (a linguagem da câmera); e c) o linguístico (a linguagem usada). Não há um padrão de formato de roteiro estabelecido, mas o roteiro de $\mathrm{AD}$ para a televisão e o cinema é geralmente confeccionado contendo os seguintes itens: a) o TCR, que indica a entrada e saída do texto da audiodescrição; b) o texto da audiodescrição; c) as deixas, que são as últimas falas antes de entrar a $\mathrm{AD}$; e d) as rubricas, que são as instruções para a locução (falar rápido, leve sobreposição etc.). ${ }^{9}$ Uma amostra desse roteiro pode ser vista na Figura 2.

\footnotetext{
${ }^{9}$ O grupo TRAMAD (Tradução, Mídia e Audiodescrição), da UFBA, por exemplo, nunca incluiu o número sequencial no roteiro e deixou de incluir as "deixas" após sugestão de um estúdio de dublagem em São Paulo, para o qual realizou audiodescrições de três longas-metragens. O TCR de entrada e saída do texto da AD aparece, por sua vez, em linhas diferentes, e não na mesma linha, como a Figura 2 ilustra. Tais modificações foram sugeridas para que o roteiro de audiodescrição fique parecido com o roteiro de dublagem, o que facilita o trabalho de locutores dos estúdios, já acostumados com o formato deste último.
} 
FRANCO \& ARAÚJO - Questões terminológicas e conceituais ...

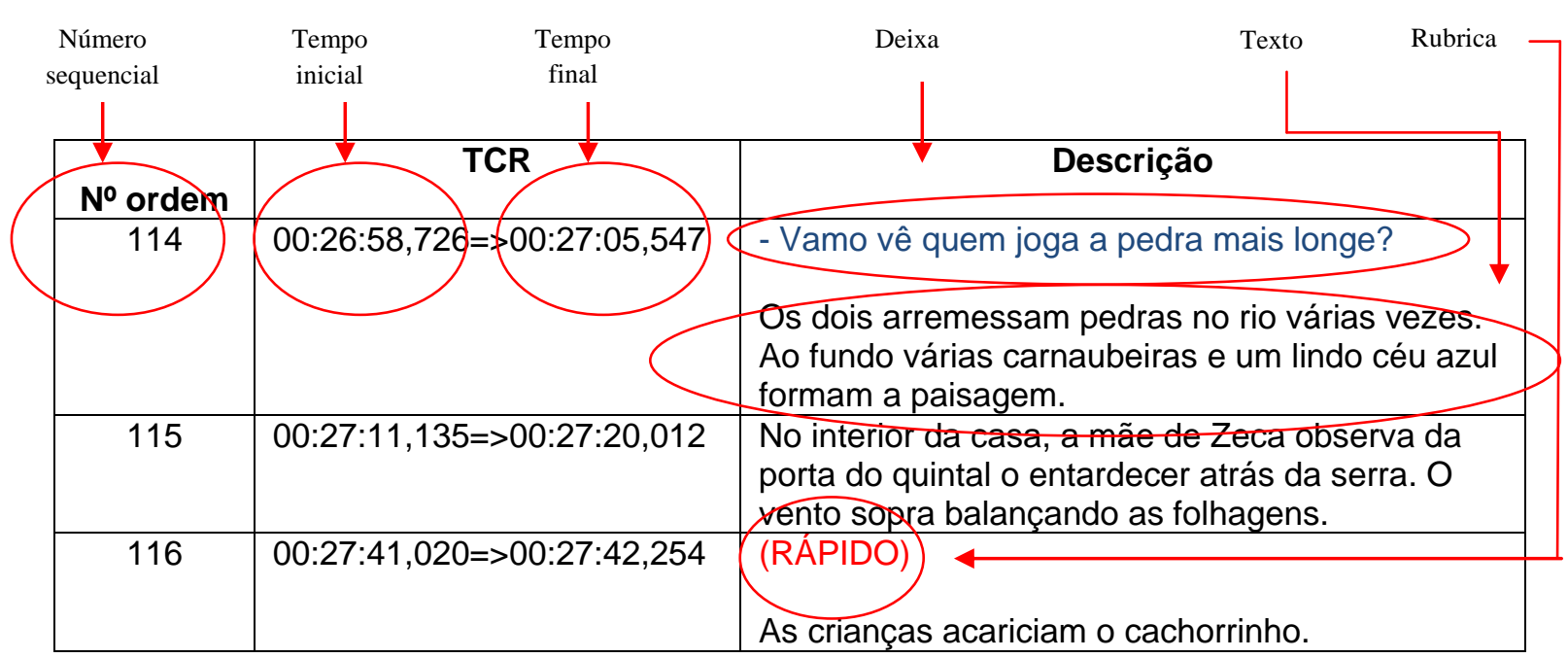

Figura 2: Roteiro de Audiodescrição

Depois de gravada a locução, a AD é editada e mixada ao som da trilha sonora do filme ou programa de TV. Utilizando um programa de edição de som, a faixa da AD é editada, eliminando-se os ruídos, equalizando-se a voz gravada (grave, médio, agudo), e ajustando-se o volume, a fim de torná-la inteligível e o mais agradável possível aos ouvidos do público. Em seguida, utilizando um programa de edição de vídeo, a AD é incorporada ao filme ou programa, encaixando-se as inserções no tempo exato e equalizando-se as duas trilhas sonoras, de forma que ambas alcancem os mesmos níveis de áudio.

Existe uma discussão acirrada sobre a necessidade de expressividade da voz na locução da AD. Benecke (2004) defende que a mesma seja pouco expressiva e sem inflexões para que a pessoa com deficiência visual não confunda a $\mathrm{AD}$ com as falas do filme ou programa. Iglesias (2010), por outro lado, pensa exatamente o contrário: uma locução expressiva pode dar significado diferente à AD; as ênfases na locução tornariam a experiência mais prazerosa para o espectador cego. Na opinião das presentes autoras, que já pesquisaram essa questão em testes de recepção, uma voz expressiva sem exageros e que acompanhe o ritmo do filme provou ser essencial para tornar a descrição ainda mais eficiente para o público com deficiência visual.

A AD ao vivo pode ser realizada com e sem roteiro (Matamala, 2007). No primeiro caso, é o que acontece no teatro em uma peça ou dança. Um roteiro é confeccionado com base num vídeo gravado do último ensaio, idealmente em duas versões, uma panorâmica do palco e outra focada nos detalhes da ação no palco, e no próprio roteiro final da peça, onde o texto da audiodescrição será inserido. Nesse caso, não é necessário adicionar TCR pois tudo acontece na hora. No caso da dança, não há o 
FRANCO \& ARAÚJO - Questões terminológicas e conceituais ...

roteiro escrito, mas apenas o DVD para dirigir o trabalho do audiodescritor/roteirista. No dia da apresentação, o audiodescritor/locutor fica numa cabina ou na sala de som do teatro e a $\mathrm{AD}$ chega aos espectadores por meio de fones, semelhantes aos equipamentos usados numa interpretação simultânea. Apesar da importância do roteiro, a AD ao vivo no teatro exige que o audiodescritor/locutor não tire os olhos do palco, uma vez que imprevistos podem acontecer a cada apresentação. A AD de eventos ou programas ao vivo, por vezes chamada de "audiodescrição simultânea", já é totalmente improvisada e sem roteiro, uma vez que nunca se sabe o que pode acontecer num produto audiovisual desse tipo.

Ainda no que diz respeito à $\mathrm{AD}$ ao vivo, é relevante citar o caso da $\mathrm{AD}$ de óperas, que normalmente ocorrem numa língua estrangeira e, por essa razão, precisam ser legendadas. Então, para o audiodescritor/locutor é dada mais uma tarefa. Além de audiodescrever as cenas do palco, o profissional necessita ler as legendas. É o que Orero (2007) chama de audiosubtitling ou "audiolegendagem". A audiolegendagem pode ser realizada também em filmes, como a que aconteceu na $\mathrm{AD}$ brasileira do filme Ensaio sobre a Cegueira (Fernando Meireles, 2008). Na versão audiodescrita do DVD, foram mantidos os diálogos em japonês, os quais foram legendados para os videntes e lidos para os deficientes visuais. Seja para o teatro ou para o cinema, o DVD e a TV, é recomendável que a audiolegendagem seja desempenhada por uma voz diferente daquela que está realizando a audiodescrição, para o melhor entendimento das funções de cada uma no produto audiovisual pelo público-alvo.

A pesquisa em $\mathrm{AD}$ no Brasil é recente, mas já conta com algumas publicações. Os livros de Motta e Romeu Filho (2010) e Santos (2010), além do número especial sobre tradução audiovisual do periódico TradTerm (Franco \& Araújo, 2007), já mencionado na introdução do presente artigo. Todos tratam de questões legais, profissionais e acadêmicas, versando sobre a $\mathrm{AD}$ de diferentes gêneros audiovisuais. Além disso, já existem quatro dissertações de mestrado defendidas. Dentre elas, três (Silva, 2009; Vilaronga, 2010 e Braga, 2011) enfocam a AD no meio audiovisual sob diferentes perspectivas e uma (Oliveira Junior, 2011) discute a AD de obras de arte.

\section{Considerações Finais}

A discussão terminológica e conceitual no âmbito da TAV aqui realizada não pretendeu ser exaustiva e nem dar a última palavra sobre a questão, mas propor um ponto de partida para o debate sobre o assunto entre pesquisadores e profissionais da área, 
FRANCO \& ARAÚJO - Questões terminológicas e conceituais ...

academia e mercado, com o intuito de chegarmos a um consenso e afinarmos o discurso dentro do campo da tradução audiovisual em nosso país, campo esse que vem despertando interesse cada vez maior devido à recente obrigatoriedade da implementação de recursos de acessibilidade, como a LSE e a AD.

Esse consenso deve abranger questões ainda mais básicas do que as discutidas aqui, como a grafia que adotaremos para nomear os modos de TAV. Apesar de frequentemente usados em textos da área no português brasileiro, os termos "audiovisual" e "audiodescrição" escritos sem hífen ou acento não são unanimidade entre pesquisadores do país por constituírem calque da língua inglesa. Também o termo voice-over, traduzido por alguns pesquisadores para suas línguas maternas, ainda não encontrou substituto em nossa língua, ou talvez isso nunca seja necessário ou desejável.

Se o intuito é aprofundar os estudos e investir cada vez mais na qualidade dos produtos audiovisuais traduzidos oferecidos aos espectadores brasileiros, a homogeneidade gráfica, terminológica e conceitual é condição sine qua non para introduzir qualquer diálogo entre pesquisadores e profissionais na área,

\section{Referências bibliográficas}

ALVARENGA, L. Subtitler: legendador ou legendista. In: Anais do I Congresso Ibero-Americano de tradução e Interpretação (I CIATI): Tradução, Intepretação e Cultura na Era da Globalização. São Paulo: UNIBERO, 1998. p. 214-216.

ARAÚJO, V.L.S. To be or not to be natural, eis a questão dos clichês da emoção na tradução audiovisual. São Paulo, 2000. Tese (Doutorado em Letras). FFLCH, Universidade de São Paulo.

AGOST, R. Traducción y doblaje: Palabras, voces e imágenes. Barcelona: Ariel, 1999.

BALLESTER CASADO, A. Traducción y nacionalismo: la recepción del cine americano en España através del doblage. Granada, 1999. Tese de Doutorado. Universidad de Granada, Espanha.

BARTOLL, E. The surtitling in Catalan of classic foreign theatre plays. In INCALTERRA, L; BISCIO, L; MHAINNIN, M.A.N. Audiovisual Translation: Subtitles and Subtitling. Oxford: Peter Lang, 2011. p. 87-108.

BENECKE, B. Audio-description. Gambier, Y. (Ed.) Meta. Volume 49, n. 1, 2004, 7880. 
BRAGA, K.B. Cinema acessível para pessoas com deficiência visual: a audiodescrição de $\boldsymbol{O}$ Grão de Petrus Cariry. Fortaleza, 2011. Dissertação (Mestrado em Linguística Aplicada). Universidade Estadual do Ceará.

CARVALHO, C. A. Singularidade transgressão e ética na legendagem. Linguagem em Foco, n. 2, p. 27-38, 2009.

CHAUME, F. Cine y traducción. Madrid: Cátedra, 2004.

DIAZ CINTAS, J. Audiovisual Translation Today. A question of accessibility for all. Translating Today, v. 4, p. 3-5, 2005.

DOANE, M. A. (1985) The Voice in the cinema: The articulation of body and space. In: WEIS, Elisabeth \& BELTON, John (Eds). Film Sound: Theory and practice. New York: Columbia University Press, 1985. p.163-176.

FRANCO, E. P. C. Everything you wanted to know about film translation (but did not have the chance to ask). Florianópolis, 1991. Dissertação (Mestrado em Letras). Universidade Federal de Santa Catarina.

Revoicing the Alien in Documentaries: Cultural Agency, Norms and the Translation of Audiovisual Reality. Leuven, 2000. Tese (Doutorado em Letras). Universidade Católica de Leuven, Bélgica. Disponível em: http://tede.ibict.br/tde_arquivos/1/TDE-2005-02-23T06:09:47Z-

94/Publico/ElianaPCFranco.pdf.

Voiced-over television documentaries: Terminological and conceptual issues for their research. Target, 13(2), p. 289-304, 2001.

FRANCO, E.; MATAMALA, A.; ORERO, P. Voice-Over Translation: An Overview, Bern/Berlin: Peter Lang, 2010.

FRANCO, E.P.C. \& ARAUJO, V.L.S. (Orgs.) Dossiê Tradução Audiovisual. Cadernos de Tradução, v.2, n. XVI, Florianópolis: Edufsc, 2005.

(Orgs.) TradTerm, v. 13, São Paulo: Humanitas (FFLCH-USP), 2007.

FREDDI, M.; LURAGHI, S. Titling for the opera house: a test case for universals of translation? In: INCALTERRA, L; BISCIO, L; MHAINNIN, M.A.N. Audiovisual translation: subtitles and subtitling. Oxford: Peter Lang, 2011. p. 55-86.

GAMBIER, Y. La traduction audiovisuelle un genre nouveau? In GAMBIER, Y. (Ed.) Les transferts linguistiques dans les médias audiovisuels. Villeneuve d'Ascq: Presses Universitaires du Septentrion, 1996. p. 7-12.

Introduction: Screen Transadaptation: Perception and Reception. The Translator. Special issue on Screen Translation, v. 9, n. 2, p. 191-205, 2003. 
FRANCO \& ARAÚJO - Questões terminológicas e conceituais ...

(Ed.) La traduction audiovisuelle: Un genre en expansion. Meta, 49 (1), p. 1-11, 2004.

HARRINGTON, J. The rhetoric of film. New York: Holt, Rinehart and Winston, 1973.

JAKOBSON, R. On Linguistic Aspects of Translation. In: BROWER, R. A. (Ed.) On Translation. Cambridge, MA: Harvard University Press, 1959. p. 232-239.

JIMENÉZ, C. Un corpus de cine. Fundamentos metodológicos y aplicados de la audiodescripción. In: JIMENÉZ, C.; RODRÍGUEZ, A.; SEIBEL, C. Un corpus de cine. Teoría y práctica de la audiodescripción. Granada: Ediciones Tragacanto, 2010. p. 57-110.

IGLESIAS, E. La dimension paralinguística de la audiodescripción: un acercamiento multidisciplinar. In: JIMENÉZ, C.; RODRÍGUEZ, A.; SEIBEL, C. Un corpus de cine. Teoría y práctica de la audiodescripción. Granada: Ediciones Tragacanto, 2010. p. 205-224.

KAUFMANN, F. Formation à la traduction et à l'interprétation pour les médias audiovisuels. In GAMBIER, Y. (Ed.) Communication audiovisuelle et transferts linguistiques. Audiovisual communication and language transfers (International Forum, Strasbourg, 22-24 June 1995). Special issue of Translatio (FIT Newsletter / Nouvelles de la FIT), p. 431-442, 1995.

LUYKEN, G.-M.; HERBST, T.; LANGHAM-BROWN, J.; REID, H.; SPINHOF, H. Overcoming language barriers in television: Dubbing and subtitling for the European audience. Media Monographs n. 13, Manchester: The European Institute for the Media, 1991.

MARTINEZ, S. L. Tradução para legendas: uma proposta para a formação de profissionais. Rio de Janeiro, 2007. Dissertação (Mestrado em Letras - Estudos da Linguagem). Pontifícia Universidade Católica do Rio de Janeiro.

MATAMALA, A. La audiodescripción en directo. In: HURTADO, C.J. Traducción y acessibilidad. Berlin: Peter Lang, 2007. p. 121-132.

MOTTA, L.M.V.M. \& ROMEU FILHO, P. (Orgs.) Audiodescrição: transformando imagens em palavras. São Paulo: Secretaria de Estado dos Direitos da Pessoa com Deficiência, 2010.

OLIVEIRA JUNIOR, J.N. Ouvindo imagens: a audiodescrição de obras de Aldemir Martins. Fortaleza, 2011. Dissertação (Mestrado em Linguística Aplicada). Universidade Estadual do Ceará.

ORERO, P. Audiosubtitling: a possible solution for opera accessibility in Catalonia. TradTerm, n. 13, p. 135-149, 2007. 
ORERO, P. Subtitulado por reconocimiento del habla: una potente herramienta para la accesibilidad. Disponível em: http://www.coitt.es/res/DiadaWeb/Subtitulado\%20por\%20reconocimiento\%20del s/d. Acesso em 24 nov. 2011.

RABIGER, M. Directing the documentary. Third edition. Boston: Focal Press, 1998.

RIBAS, M.A.; ROMERO FRESCO, P. A Practical Proposal for the Training of Respeakers. Journal of Specialised Translation. Disponível em: http://www.jostrans.org/issue10/art_arumi.php, 2008. Acesso em 24 nov. 2011.

ROMERO FRESCO, P. La subtitulación rehablada: palabras que no se lleva el viento. In: PÉREZ-UGENA, A.; VIZCAÍNO-LAORGA, R. (Eds.) ULISES: Hacia el desarrollo de tecnologías comunicativas para la igualdad de oportunidades. Madrid: Observatorio de las Realidades Sociales y de la Comunicación, 2009. p. 49-73.

ROMERO FRESCO, P. Standing on quicksand: Hearing viewers' comprehension and reading patterns of respoken subtitles for the news". In DÍAZ CINTAS, J.; MATAMALA, A.; NEVES, J. (Eds.) New Insights into Audiovisual Translation and Accessibility. Media for All 2, Amsterdã: Rodopi, 2010. p. 175195.

ROXO, E.; RODRIGUES, L. V. TV paga vira dublada e "esquece" som original", Folha de São Paulo, outubro 2011.

SANTOS, A.P. Diálogos entre arte e público: acessibilidade cultural: o que é acessível e para quem? Fundação de Cultura da Cidade do Recife, 2010.

SELVATICI, C. Closed caption: conquistas e questões. Rio de Janeiro, 2010. Dissertação (Mestrado em Letras - Estudos da Linguagem). Pontifícia Universidade Católica do Rio de Janeiro.

SILVA, M. C. Com os olhos do coração: estudo acerca da audiodescrição de desenhos animados para o público infantil. Salvador, 2009. Dissertação (Mestrado em Linguística). Universidade Federal da Bahia.

VILARONGA, I. O Potencial Formativo do Cinema e a Audiodescrição: Olhares Cegos. Salvador, 2010. Dissertação de Mestrado. Universidade Estadual da Bahia.

WHITMAN, C. Through the dubbing glass, Frankfurt: Peter Lang, 1992. 